\title{
ПРИБОРОСТРОЕНИЕ
}

\section{УДК 621.362}

Гаджиева С.М., Челушкин Д.А.

\section{ТЕРМОЭЛЕКТРИЧЕСКОЕ ПОЛУПРОВОДНИКОВОЕ УСТРОЙСТВО С ВЫСОКИМ ГРАДИЕНТОМ ТЕМПЕРАТУР}

\author{
Gadjiyeva S.M., Chelushkin D.A.
}

\section{A THERMOELECTRIC SEMICONDUCTOR DEVICE WITH A HIGH TEMPERATURE GRADIENT}

В статье рассмотрено термоэлектрическое устройство, у которого нагретье спаи пространственно отдалены от холодных спаев для уменьшения паразитных кондуктивных потерь между этими спаями.

Ключевые слова: термоэлектрическое устройство, градиент температур, паразитные кондуктивные потери.

In the article the thermoelectric device, which heated junctions spatially distant from the cold junctions to reduce parasitic losses between the conductive junctions.

Key words: thermoelectric device, temperature gradient, conductive parasitic losses.

С повышением быстродействия и мощности современной электронной аппаратуры возрастает актуальность применения эффективных систем охлаждения. Наиболее перспективными в этой области являются термоэлектрические устройства на основе эффекта Пельтье. Однако не все теплофизические процессы в ТЭУ изучены в достаточной степени и используются не в полном объеме при конструировании ветвей и спаев ТЭУ. В частности, недостаточно исследован механизм и физический смысл процесса теплообмена при переходе электронов из полупроводника с различными типами проводимости в металл. Обратный переход также слабо исследован. Однако внимательное изучение этих механизмов позволяет более грамотно спроектировать конструкцию ТЭУ. Важную роль в этом процессе играет процесс теплообмена движущегося заряда вблизи границы перехода из полупроводника в металл и из металла в полупроводник. Проведенные исследования позволяют сделать вывод, что процесс теплообмена можно разделить пространственно в пределах одного спая, т.е. нагрев и охлаждение в определенной степени происходит на одном и другом конце спая, что позволяет спроектировать более эффективную конструкцию с расположением всех нагретых участков в одной плоскости, а всех холодных участков в другой.

Рассмотрим электротеплофизические процессы в традиционных термоэлементах. Термоэлемент содержит две ветви $n$ - и $p$-типа проводимости поперечными сечениями $\mathrm{s}_{1}$, $\mathrm{s}_{2}$ и длинойl(рис. 1). Материал ветвей однороден и изотропен, температурной зависимостью свойств материала пренебрегаем [1]. Горячие спаи, по которым к термоэлементу подводится электрический токтермостатированы при температуре $T_{0}$. Боковые поверхности ветвей термоэлемента адиабатически изолированы. Если направление тока через термоэлемент таково, что на термостатированных спаях тепло Пельтье выделяется, а на противоположных - поглощается, то в термоэлементе происходит охлаждение.

Расчет простейшей модели производится для одномерного распределения температуры, стационарных условий, при учете эффекта Пельтье на спаях и выделении 
тепла Джоуля в объеме (эффектом Томсона пренебрегаем). Для таких условий можно принять, что половина тепла Джоуля из ветвей термоэлемента переносится холодным спаям, а половина - горячим. Таким образом, тепло, поглощаемое холодным спаем,

$$
Q=-\Pi I+\frac{1}{2} I^{2} r
$$

гдеП - коэффициент Пельтье, $r$ - сопротивление термоэлемента. Из (1) следует (рис. 2) наличие оптимальноготокапри котором достигается наибольшее охлаждение: при меньших токах теплопоглощение эффектом Пельтье убывает, при больших - возрастает роль тепла Джоуля. Холодным спаем поглощается также тепло, переносимое ветвями термоэлемента от горячих спаев, и $Q_{0}$ тепло, генерируемое охлаждаемым объектом или переносимое при теплообмене холодным спаям от окружающей среды. Различают три основных режима работы термоэлемента: максимального перепада температуры или максимального охлаждения, максимальной холодопроизводительности и максимального холодильного коэффициента, или максимальной экономичности. Иногда используют и другие режимы: минимального тока, промежуточный, принудительный, тепловой изоляции.

Режим максимального перепада температуры достигается при $Q_{0}=0$, баланс теплот на холодном спае записывается в виде

$$
\chi_{0}\left(T_{0}-T_{1}\right)=-\Pi I+\frac{1}{2} I^{2} r
$$

где $\chi_{0}$ - теплопроводность ветвей, $\mathrm{T}_{1}$ - температура на холодном спае.

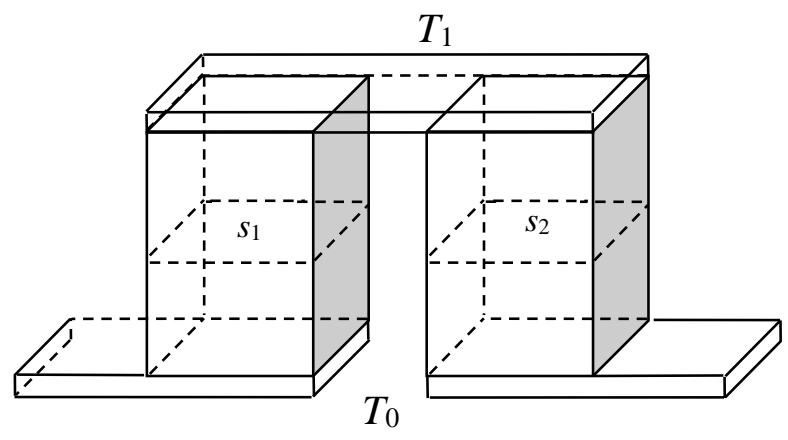

Рисунок 1 - Схема охлаждающего термопарного элемента, действие которого основано на эффекте Пельтье

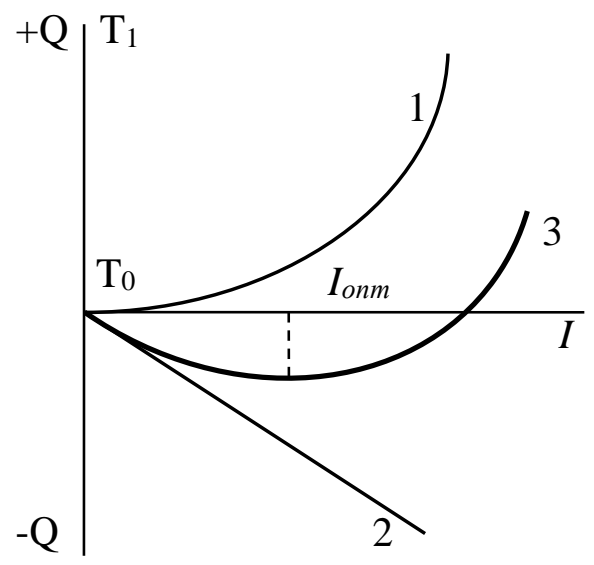

Рисунок 2 - Графики, демонстрирующие зависимость охлаждения от тока через термоэлемент: 1 - тепло Джоуля; 2 - поглощенное в спае тепло (эффект Пельтье); 3 температура холодного спая 
Из (1) и (2) следует

$$
\begin{gathered}
I_{T_{1}}^{\text {onm }}=\frac{\Pi}{r}, \\
Q^{\text {макс }}=\frac{\Pi^{2}}{2 r} .
\end{gathered}
$$

Максимальный перепад температуры

$$
\left(T_{0}-T_{1}\right)_{\text {макс }}=\frac{\Pi^{2}}{2 \chi_{0} r},
$$

где

$$
r=l\left(\frac{1}{\sigma_{1} s_{1}}+\frac{1}{\sigma_{2} s_{2}}\right), \quad \chi_{0}=\frac{1}{l}\left(\chi_{1} s_{1}+\chi_{2} s_{2}\right),
$$

$\sigma_{1} \sigma_{2}$ - электропроводности материалов ветвей, $\chi_{1}$ и $\chi_{2}-$ их коэффициенты теплопроводности. Кроме оптимизации по току, из (5) и (6) определяется соотношение между параметрами материала и площадями поперечного сечения ветвей, при котором достигается максимальный перепад температуры:

$$
\frac{s_{2}}{s_{1}}=\sqrt{\frac{\chi_{1} \sigma_{1}}{\chi_{2} \sigma_{2}}}
$$

а при ветвях термоэлементов различной длины $l_{1} l_{2}$

$$
\frac{s_{2} l_{1}}{s_{1} l_{2}}=\sqrt{\frac{\chi_{1} \sigma_{1}}{\chi_{2} \sigma_{2}}}
$$

С учетом (7), (8) выражение (5) приводится к виду

$$
\left(T_{0}-T_{1}\right)_{\text {макс }}=\frac{1}{2} Z_{0} T_{1}^{2}
$$

где

$$
Z_{0}=\left[\frac{\alpha_{1}-\alpha_{2}}{\sqrt{\frac{\chi_{1}}{\sigma_{1}}}+\sqrt{\frac{\chi_{2}}{\sigma_{2}}}}\right]^{2}
$$

$\alpha_{1}$ и $\alpha_{2}$ - коэффициенты термо-ЭДС материалов ветвей. Температура холодного спая определяется выражением

$$
T_{1}^{\text {мин }}=\frac{\sqrt{1+2 T_{0} Z_{0}}-1}{Z_{0}} .
$$

При наличии тепловой нагрузки уравнение баланса теплот (2) принимает вид $Q_{0}$

$$
\left(\alpha_{1}-\alpha_{2}\right) I T_{1}-\frac{1}{2} I^{2} r-\chi_{0}\left(T_{0}-T_{1}\right)-Q_{0}=0 .
$$

Из (12) следует, что режим максимальной холодопроизводительности, при котором $Q_{0}=Q_{0}^{\text {макс }}$, достигается при удовлетворении условиям (3), (7) или (8).Разность температур 
в режиме максимальной холодопроизводительности

$$
\left(T_{1}-T_{2}\right)=\left(T_{0}-T_{1}\right)_{\text {макс }}-\frac{Q_{0}}{\chi_{0}} .
$$

Для описания режима максимальной экономичности вводится холодильный коэффициент

$$
\varepsilon=\frac{Q_{0}}{W}
$$

где

$$
W=I^{2} r+\left(\alpha_{1}-\alpha_{2}\right)\left(T_{0}-T_{1}\right) I
$$

- электрическая мощность, затрачиваемая в термоэлементе.

Известен термоэлектрический модуль [2] с расположением горячих и холодных спаев в двух параллельных плоскостях. Однако получение значительных перепадов температур сталкивается с проблемой паразитного кондуктивного переноса между горячими и холодными спаями. Увеличение высоты полупроводниковых ветвей приводит к увеличению их сопротивления и, как следствие, к увеличению джоулевых тепловыделений, что также снижает эффективность термомодуля. Анализ тепловых процессов в металлических спаях выявляет неоднородность тепловыделения на протяжении спая. Основной теплообмен происходит в той части спая, куда входит электрический ток из полупроводниковой ветви. Учет этой неоднородности позволяет таким образом сформировать термомодуль, что горячие и холодные участки спаев могут быть более плотно сконцентрированы для получения более эффективного теплообмена.

Это достигается тем, что полупроводниковые ветви $p$-типа и $n$-типа расположены таким образом, что все ветви $p$-типа находятся в одной плоскости, а все ветви $n$-типа в другой параллельной плоскости, поэтому нагретые спаи пространственно отдалены от холодных спаев, что уменьшает паразитные кондуктивные потери между спаями.

На рис. 3 представлена принципиальная схема термоэлектрического устройства с высоким градиентом температур.

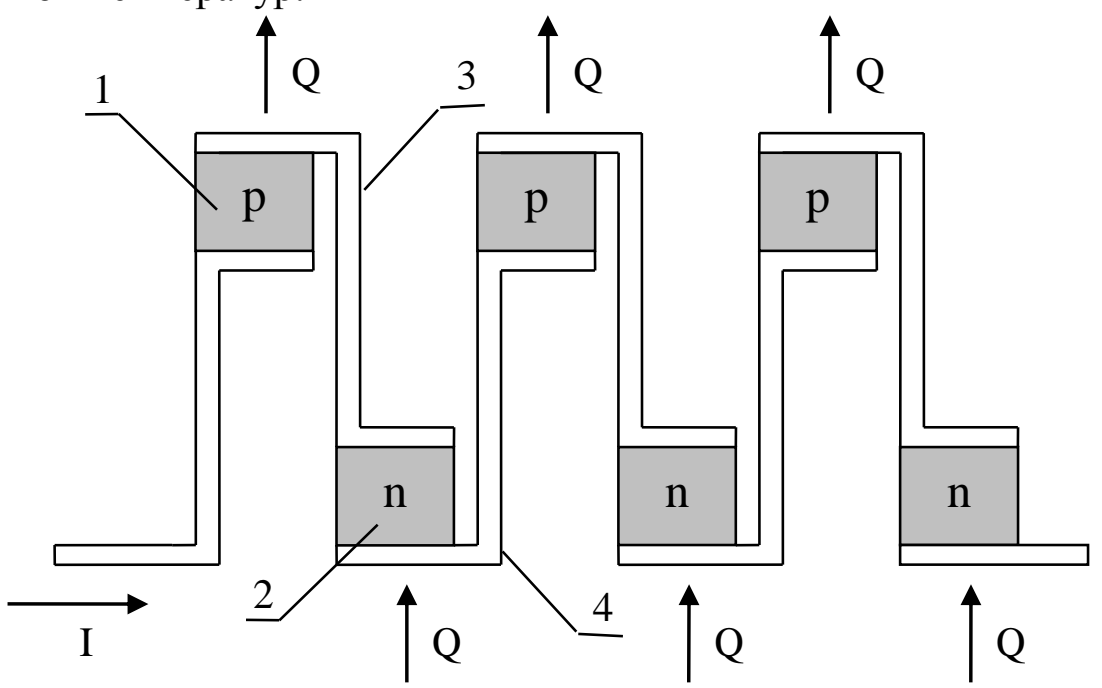

Рисунок 3 - Принципиальная схема термоэлектрического устройства с высоким градиентом температур

Конструкция термоэлектрического устройства представляет собой полупроводниковые ветви $p$-типа 1 и $n$-типа 2, расположенные в разных плоскостях, таким образом, что при пропускании тока возникает чередование горячих 3 и холодных 4 спаев, причем за счет большой длины спаев основной теплообмен происходит вблизи перехода между полупроводниковой ветвью и спаем. Это обусловлено тем, что заряд, имеющий ограниченную длину свободного пробега, после одного или двух соударений с 
кристаллической решеткой металлического спая полностью обменивается с ней энергией. Поэтому нагрев или охлаждение спая будет происходить только с того конца, где электроны попадают в металлический спай из полупроводника.

Использование представленного устройства позволит создать термомодули с высоким градиентом температур за счет уменьшения кондуктивных паразитных потерь между горячими и холодными спаями, а также за счет более плотной компоновки ветвей, так как поверхность теплообмена будет состоять не из всего металлического спая, а только из его нагретого участка. Кроме того, если середину металлического спая выполнить в виде гибкой проводимой структуры, то термомодуль сможет формировать горячую и холодную поверхность в любых плоскостях, а не только в параллельных.

\title{
Библиографический список:
}

1. Анатычук Л.И. Термоэлектричество Т2. - Киев: Букрек, 2003. - 386 с.

2. Патент РФ, № 2335825. Термоэлектрическое устройство с высоким градиентом температур/Исмаилов Т.А., Гаджиев Х.М., Гаджиева С.М. Опубл. 10.10.2008. Бюл. 28.

\section{УДК 681.382}

Казумов Р.Ш.

\section{КОНСТРУКЦИИ УСТРОЙСТВ ДЛЯ НЕРАВНОМЕРНОГО ОХЛАЖДЕНИЯ ЭЛЕКТРОННЫХ ПЛАТ С ПРИМЕНЕНИЕМ ТЕРМОЭЛЕКТРИЧЕСКОГО МЕТОДА ПРЕОБРАЗОВАНИЯ ЭНЕРГИИ}

\author{
Kazumov R.Sh.
}

\section{CONSTRUCTION OF THE DEVICES FOR PRINTED CIRCUIT BOARDS, IRREGULAR FREEZING USING THERMOELECTRIC ENERGY CONVERSION}

В статье рассмотрены различные конструктивные варианты устройств для охлаждения электронных плат.

Ключевые слова: электронная плата, термоэлектрическая батарея, плавящееся вещество, теплоотвод, конструкция.

The article considering the different design options for cooling electronic devices boards.

Key words: electronic board thermoelectric battery, melting substance, heat sink design.

Современные устройства радиоэлектронной аппаратуры (РЭА) характеризуются высокими локальными рассеяниями тепла, что вызывает дестабилизацию их работы и снижает надежность. Применение систем обеспечения температурных режимов на основе воздушного, водяного охлаждения или тепловых труб часто невозможно из-за эксплуатационных и массогабаритных ограничений. Поэтому решение задачи температурной стабилизации РЭА может быть получено применением в качестве систем обеспечения температурных режимов охлаждающих полупроводниковых термоэлектрических устройств (ТЭУ), оптимально сочетающихся с РЭА по важнейшим энергетическим и массогабаритным показателям.

Использование охлаждающих полупроводниковых ТЭУ позволяет применить неравномерное охлаждение, при котором различные элементы и узлы РЭА в зависимости от выделяемого тепла охлаждаются с различной степенью интенсивности [1]. В этом случае уровень теплосъема с отдельных тепловыделяющих участков РЭА определяется в 